\title{
Reflection on Project Driven LTO Teaching Method ${ }^{(1)}$
}

\author{
Hua Wang ${ }^{\text {a, }{ }^{* 1}}$, Zhijun Zheng ${ }^{\text {a, }{ }^{* 2}}$ \\ ${ }^{a}$ School of Information and Electronic Engineering, Zhejiang University of Science and Technology, Hangzhou, \\ China
}

\begin{abstract}
The traditional project driven teaching method is a popular teaching method of implementation of inquirybased teaching model. However, students have the differences of the basic knowledge resulting in increasing the difficulty of the implementation of project-driven approach. This calls for revisiting the current project driven teaching process. The proposed teaching method of LTO (Learning, Training, Operating) by extending project-driven approach is presented to resolve the problems of traditional project driven teaching method challenging to teachers at universities. The LTO teaching approach encourages more students to participate in courses and stimulates outstanding students to have more developing room. At the same time, the students are led to closely track the up-to-date technology, inspired to research knowledge in-depth. Eventually, the new values are reflected in the area of engineering education from the closed university education to the open society one and from a single classroom to actual job positions. Finally, a case study are performed to testify the efficiency of the proposed model.
\end{abstract}

Index Terms: Project Driven; Learning; Training; Operating; Open Experiments

(C) 2012 Published by MECS Publisher. Selection and/or peer review under responsibility of the International Conference on E-Business System and Education Technology

\section{Introduction}

In order to complete the task of teaching, traditional teaching experience of the course of software engineering major showed that teachers mostly talked about the general grammatical rules of programming language, and then the specific application examples were given. However, examples cited in classes was the whole code, which had been designed in advance and there is no real programming and debugging process for demonstration and real practice session in classroom. Consequently, students thought study content to be boring because theory and practice can not be combined organically. Furthermore, students had poor ability to solve practical problems, and were not active, resulting that study results were not satisfactory. In the teaching process, the effect of traditional classroom teaching methods could not achieve good teaching results. For

\footnotetext{
${ }^{(1)}$ This work has been partially sponsored by the University Level Teaching and Research Project Foundation at Zhejiang University of Science and Technology under grant 2009 II B-a17.

* Corresponding author:

E-mail address: ${ }^{* 1}$ wanghua96@126.com; ${ }^{* 2}$ zjzheng9999@ sina.com
} 
teachers, individualized teaching, adjusting the teaching content, the reform of teaching methods, assessment methods and other measures of innovation are very important.

A lot of literatures have contributed to the project-driven teaching method. Rui presented a project designed for a power electronics and drives course[1]. Each part of the project and the student assessment are described. A method put forward that project management technology was applied to project-driven teaching model through tutorial system[2]. A case study was concerned with the development, maturation, and reuse of a business domain independent software component (horizontal reuse) in a project-driven organization that had little previous experience with systematic software reuse[3]. Shiokova designed a hybrid model[4] which combined face-to-face instruction with the approaches of distance learning and multimedia methods to integrate modern learning methods and technologies into traditional university teaching. Kolar and Sabatini launched a classroom reform[5] and the paradigm centered on project-driven assignments, by which they mean students an organized into teams and given a complex design question at the beginning of the semester before any substantive background material was delivered. Wan and Gao established the theoretical model for projectdriven teaching in CEM (construction engineering management) under the framework of cognitive theory[6]. A report was given on practice of actual project driven teaching model on software engineering major[7]. More relevant research were found in [8-10].

The project driven teaching method is a popular teaching method of implementation of inquiry-based teaching model. However, students have the differences of the basic knowledge resulting in increasing the difficulty of the implementation of project-driven approach. The teaching method of LTO (Learning, Training, Operating) by extending project-driven approach is presented to resolve the problems of traditional project driven teaching method. Meanwhile, CMM (Capability Maturity Model for Software) software process management by means of demonstration project of development process is employed, so that students really master the commercial software development method and process.

The proposed method can strengthen students with more powerful practical ability gradually through different training phrase. Firstly, the cultivation goal of applied talents could be achieved. Secondly, software development process could be standardized, students could understand the essence of CMM and improve their sense of teamwork, and students can have cognition and feelings towards software development through the project-driven LTO method. Thirdly, the proposed method can promote students with the ability of Java programming, database theory and software engineering courses. Finally, when students are no longer forced to take learning as a task, but to learn according to the requirements of the project. And the study mode is changed from passive recipients of knowledge to the initiative to seek knowledge. Autonomous learning, problem analysis and problem solving skills will be cultivated. Students will get a better experience of the project to lay a good foundation for the future of software career.

\section{Project Driven LTO Teaching Method}

Learning activities must be combined with the task or issue. Students should study with the task in real software project situations. The way of exploring and solving problems is proposed to drive and sustain the interest and motivation of learners. Compared to other courses, software development courses have the strong features of practice, engineering, integration, abstraction. The traditional teaching method requires that students should remember many boring concepts and syntax details at each class, but do not know how to coordinate them to solve practical problems. The project driven LTO teaching method is an original and efficient method to resolve the difficulties in the traditional teaching method. The prior method is challenged by three important questions. Firstly, the selection and positioning software project should be appropriate. Software projects involved students have a special nature that there are often uncertain factors that can affect the progress of the target project, such as interim and final exams, class activities and even university lectures. Therefore, the decomposition of the project under consideration, the development model, reducing uncertain factors and other issues are to be explored. Secondly, how is the knowledge merged into three different stages of LTO in the study process to maintain the three stages (Learning, Training, Operating) to be seamless? Thirdly, how is the 
enthusiasm of project members maintained? Project involved students is not the same as full-time practical business projects. Accordingly, there are not too many hard targets to manage the members. Project cycle, weekly meeting, the project's goals call for specially reconsidered. We elaborate as follows.

\subsection{Learning, Training and Operating}

- Learning: In the process of teaching, two main lines are followed. The first line is the progress of the software development cycle and task partitioning considering the characteristics of software development courses. The second line is to follow the idea of practice driving theoretical study. Growth line of the ability to learn is integrated in-depth with the above idea: project drives ability, ability promotes knowledge from the knowledge to the theory and finally the theory generates ability.

- Training: Each class takes modules of the project as tasks and focuses on process-oriented structure. The tasks drives knowledge. Students are inspired to operate and build the development team of software project. Team members strictly abide by the enterprise development process and specification, for example CMMI (Capability Maturity Model Integration for software). The functional modules and the development cycle are closely combined.

- Operating: The software company's actual project management process specification is referred as project management process in class. PSP (Personal Software Process) and TSP (Team Software Process) are employed to guide the process of project implementation in-depth. The necessary assistance is provided by teachers to promote the communication within the project and among projects. The project team need borrow some valuable technical material. The project team have to have weekly project regular meeting that is necessary to control the development process. This must be conformed, otherwise, the activity is easily omitted. Do not need to pay attention to the form of regular meetings, but must be results-oriented.

The LTO teaching method can be illustrated as Fig. 1.

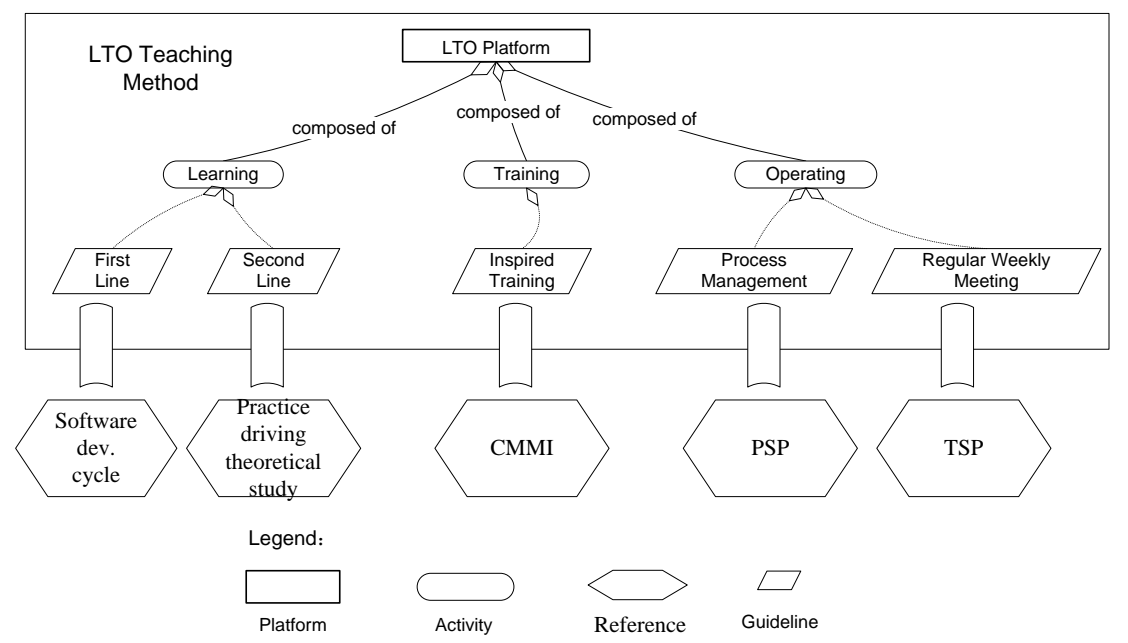

Fig. 1. LTO Teaching Architecture

The LTO teaching architecture follows the guidelines of learning from project development and exercising from practice. After applying LTO teaching method, the goal is to make students like this course and they get better experience in software development. At the end of the project, the project team members will have become good friends, overcoming the weaknesses of poor communication for students in traditional technology courses. 


\subsection{The Key Points in LTO Teaching Architecture}

There are several key points in the LTO teaching architecture to be addressed as follows.

- Project Candidates: The choice of case project executed by students is an important issue, as discussed before. There are two methods to determine what types of projects are appropriate to the target students. One is to give students some candidates of projects and the other is to let students themselves design the subject of projects. In the first case, the teacher should find out the study level of students because the students with different levels have different ability of study and programming skills.

- Task Analysis: After determining the task, teachers should not directly tell the students how to solve problems, but analyze the basic concepts of textbook content and the structure of relevant knowledge. Ways and means are provided to get more information and resources. Teachers guide students to learn self-claim, emphasizing self-learning ability of students. During teaching, teachers should break the traditional division of chapters and explain concepts and principles relevant to each task, while omitting those irrelevant contents.

- On-demand Learning and Communication: Students are divided into several groups according to cognitive level, aptitude, personality characteristics, etc. Collaborative learning of group advocates discussions and exchanges among students. Through confrontation and collision of different perspectives, the LTO teaching method supplements, amendments and deepen each student's understanding of current issues, furthermore, improves and deepens the learning of individual mastery of knowledge. The role of teachers in this aspect is mainly inspiration and induction. After finishing such a class, all students have the harvest and everyone has achievements thus achieving truly individualized teaching.

- Feedback and Summary: From the point of view of control theory, any system should be a controlled closed-loop system. To ensure the normal operation of teaching and continuous improvement, feedback information is of great significance. This part focuses on main problems students feedback to evaluate, analyze and summary with combination of teaching objectives. Eventually, objective evaluation of the development process of different students is realized. Evaluation of each student should pay attention to mobilize the enthusiasm of students. Incentive-based approach requires selecting outstanding students with the actual advantages aspects. Another improved-based approach motivates students in insufficient aspects to gain development.

\section{Case Study}

To evaluate our approach, we performed a simple case study where software project based on database is selected as target project. We take this project to the course of Web Application Development. The project focuses on the apartment management at universities including student management, apartment manager management and logistics management. The LTO teaching method was performed as follows.

\subsection{Design Tasks}

We designed several modules based on tasks as follows: students management, access registration, logistics management and system management.

- Students Management: View specific information on occupancy of individual students apartment; the balance of the utilities of apartment; hygiene assessments, and hand over other household items; reporting of bedroom hardware maintenance; suggestion box for complain and suggestion, etc.

- Access Registration: Register valuables in and out of apartment; realizing of registration of visitor access to apartment; registration of leaving school and return school; score entry for hygiene inspection for each week; registration of borrowing and returning keys; registration of students who return apartment in deep night and registration of violation of monthly electrical usage. 
- Logistics Management: Management of the school's apartment information; bedroom management of the apartment; registration for students according to each semester; information release; handle and response for suggestions; process the application of maintenance, etc.

- System Management: User login; modify password; users cancellation from the business system and accommodation cancellation of graduates; apartment information management; basic information of students and apartment administers management, etc.

\subsection{Learning- Knowledge and Project Material for Students}

Student should learn knowledge of GUI (Graphic User Interface) and basic JSP development skill. They should master database programming skill and understand how data flows from web pages to data persistence layer and from database to front GUI.

\subsection{Training- Demonstration of Login Funtion Module}

Teachers should demonstrate in class to explain the design of the web pages through the case of user login function module so that students understand programming ideas and difficulties. Furthermore, students should know project requirements and specific steps through specific teaching. Teachers tell clearly students know specifically how to do, what to do each step, focusing on the difficulties and detailed instructions.

\subsection{Operating- Implementation of Project}

Students create a database and relevant table used to store username and password. Then, the front web pages are designed. Database connection is created and tested. Students program with Java language to decide whether the username and password is identical with ones stored in database. Moreover, the management of username and password is programmed in Java. Finally, all these codes are debugged and tested.

\subsection{Evaluation of Project Results}

Students submit report of system design with Java code. Evaluation is based primarily overall system design, front web pages style and the quality of the preparation of program code together with the evaluation of teachers and students. Evaluation enables students to have a sense of achievement, inspire students to be interested in developing Java projects.

\subsection{Conculsion and Extension of Project}

After evaluation of project results, teachers should review and summary for the project fruits of students. Teachers and students should discuss project development summary of the valuable experience gained in the process. Teachers should consciously guide students experience that will be applied to the development of other projects. In this way, the innovative capacity of students will be cultivated. Students are encouraged to discuss the difficulties encountered in the project development process and how these difficulties are resolved. In this way, the ability to analyze and solve problems is formed.

\section{Conclusion}

After long term of exploration and application, LTO teaching approach has achieved very good results in the practice of teaching the course of Open Experiment in our university. General response of students to teacher through LTO teaching method is that students really master the software development method. With the ability of software development, students engage in their own future, full of longing and self-confidence. 
As a new mode of software engineering discipline, preliminary exploration of the teaching and research project is carried out in the initial experimental course for the Open Experiment. The proposed method encourages more students to participate in courses and stimulates outstanding students to have more developing room. At the same time, the students are led to closely track the up-to-date technology, inspired to research knowledge in-depth. Furthermore, students could master the technical difficulties and hot.

The values of application and promotion of LTO teaching method are explained as follows. Flexibility in the actual teaching for students of different levels and abilities can result in stimulating outstanding students to drive all the students. The proposed approach focuses on practical ability. Teaching goes out of the classroom and out of school, also reinforces the foundation of ability, paves a variety of platforms and expands learning space.

\section{Acknowledgements}

Thank colleagues for carefully reviewing my work to strengthen and elevate its quality. And thank the University Level Teaching and Research Project Foundation at Zhejiang University of Science and Technology.

\section{References}

[1] C. Rui Hong, et al., "Project-Based Lab Teaching for Power Electronics and Drives," Education, IEEE Transactions on, vol. 51, pp. 108-113, 2008.

[2] L.-j. Huang, et al., "The application of project management in project-driven teaching model," in Education Technology and Computer (ICETC), 2010 2nd International Conference on, 2010, pp. V4-91V4-94.

[3] H. B. Christensen and H. Ron, "A case study of horizontal reuse in a project-driven organisation," in Software Engineering Conference, 2000. APSEC 2000. Proceedings. Seventh Asia-Pacific, 2000, pp. 292-298.

[4] E. Shiokova and S. Tzanova, "Innovations in Bulgarian higher education in electronics through development of a simulation-based, project driven learning environment," in Frontiers in Education Conference, 1998. FIE '98. 28th Annual, 1998, pp. 737-741 vol.2.

[5] R. L. Kolar and D. A. Sabatini, "Coupling team learning and computer technology in project-driven undergraduate engineering education," in Frontiers in Education Conference, 1996. FIE '96. 26th Annual Conference., Proceedings of, 1996, pp. 172-175 vol.1.

[6] D. Wan and K. Gao, "Research on Project-Driven Teaching of Construction Engineering Management Based on Cognitive Theory," in Computer Sciences and Convergence Information Technology, 2009. ICCIT '09. Fourth International Conference on, 2009, pp. 1362-1366.

[7] L. Zhen, et al., "Practice of Actual Project Driven Teaching Model on Software Engineering Major," in Information Engineering and Computer Science, 2009. ICIECS 2009. International Conference on, 2009, pp. 1-4.

[8] Y. Jiang and L. Shen, "Development of embedded experiment platform on robot project-driven," in $E$ Health Networking, Digital Ecosystems and Technologies (EDT), 2010 International Conference on, 2010, pp. 129-132.

[9] Y. Mei and J. Yanjing, "The application of project-driven method in Information system Department professional practical teaching," in Educational and Information Technology (ICEIT), 2010 International Conference on, 2010, pp. V2-395-V2-398.

[10] A. J. Araujo and J. C. Alves, "A project driven digital design course using FPGAs," in EAEEIE Annual Conference, 2008 19th, 2008, pp. 42-47. 